\title{
Strategi Branding Kopi Kewadanan dalam Menghadapi Persaingan
}

\author{
Muchammad Faisal Ramadhan*, Udung Noor Rosyad \\ Prodi Ilmu Hubungan Masyarakat, Fakultas Ilmu Komunikasi, Universitas \\ Islam Bandung, Indonesia.
}

*faisalramadhanm97@gmail.com, udungnoor@yahoo.co.id

\begin{abstract}
Age is no longer a limitation in terms of enjoying a cup of coffee, a drink that is identical to the parents precisely for the time being is a drink that is very popular with many generations. The number of local coffee shops that have sprung up in Indonesia is also one of the factors causing this to happen, including Kopi Kebadanan which appears as one of the coffee shops in Banjar, West Java. Kopi Kewadanan sees several opportunities in building a coffee shop business, especially in cities that, because the numbers are quite small to make an opportunity in the face of competition. The purpose of this study is to find out how the branding strategy carried out by Coffee Entity, to find out how the implementation of the branding strategy carried out by Coffee Kebadanan, to find out the reason Coffee Entity uses Instagram social media as a branding strategy in the face of competition in the coffee shop business. The method chosen to conduct research on this branding strategy the author chose a qualitative method. This type of research is more emphasized to explore the meaning stored in a social phenomenon. That way this type of research can provide in-depth results because the data obtained is open. The strategy used in this research is a case study because this phenomenon occurs within a certain time limit and the researcher emphasizes the process. The results showed that the Branding Strategy undertaken by Kopi Kewadanan was to use Instagram social media. Kopi Kewadanan utilizes features found on Instagram such as photos, videos and Instagram stories to load content from previously created concepts. There is a planning stage that contains research, determines the concept and creates content as well as an implementation stage such as uploading the content via Instagram so that it can be seen by followers who are Banjar city residents even from outside the city.
\end{abstract}

Keywords: Branding Strategy, Competition, Kopi Kewadanan.

\begin{abstract}
Abstrak. Usia bukan lagi pembatas dalam hal untuk menikmati secangkir kopi, minuman yang identik dengan orang tua justru untuk saat ini menjadi minuman yang sangat digemari oleh banyak generasi. Banyaknya coffee shop lokal yang bermunculan di Indonesia juga menjadi salah satu faktor penyebab hal tersebut dapat terjadi termasuk Kopi Kewadanan yang muncul sebagai salah satu coffee shop yang ada di Banjar, Jawa Barat.Kopi Kewadanan melihat adanya beberapa peluang dalam membangun bisnis coffee shop khususnya di kota tersebut, karena jumlahnya yang cukup sedikit menjadikan kesempatan dalam menghadapi persaingan. Tujuan dari penelitian ini adalah untuk mengetahui bagaimana strategi branding yang dilakukan oleh Kopi Kewadanan, untuk mengetahui bagaimana implementasi dari strategi branding yang dilakukan Kopi Kewadanan, untuk mengetahui alasan Kopi Kewadanan menggunakan media sosial Instagram sebagai strategi branding dalam menghadapi persaingan bisnis coffee shop. Metode yang dipilih untuk melakukan penelitian mengenai strategi branding ini penulis memilih metode kualitatif. Jenis penelitian ini lebih ditekankan untuk menggali makna yang tersimpan pada suatu fenomena sosial. Dengan begitu maka jenis penelitian ini dapat memberikan hasil yang mendalam karena data yang didapat bersifat terbuka. Strategi yang digunakan dalam penelitian ini adalah studi kasus karena fenomena ini terjadi dalam batas waktu tertentu dan peneliti menekankan pada prosesnya. Hasil penelitian menunjukkan bahwa Strategi Branding yang dilakukan oleh Kopi Kewadanan adalah dengan menggunakan media sosial Instagram. Pihak Kopi Kewadanan memanfaatkan fitur-fitur yang terdapat pada Instagram seperti foto, video dan Instagram story untuk memuat konten dari konsep yang telah dibuat sebelumnya. Terdapat tahap perencanaan yang berisi riset, menentukan konsep dan membuat konten serta tahap pelaksanaan seperti mengunggah konten tersebut melalui Instagram agar dapat dilihat oleh followers yang merupakan masyarakat kota Banjar bahkan dari luar kota.
\end{abstract}

Kata Kunci: Strategi Branding, Persaingan, Kopi Kewadanan. 


\section{A. Pendahuluan}

Usia bukan lagi pembatas dalam hal untuk menikmati secangkir kopi, minuman yang identik dengan orang tua justru saat ini menjadi minuman yang sangat digemari oleh banyak generasi. Banyaknya coffee shop lokal yang bermunculan di Indonesia juga menjadi salah satu faktor penyebab hal tersebut dapat terjadi, termasuk beberapa wilayah seperti di Jawa Barat.

Kopi Kewadanan merupakan salah satu coffee shop yang berdiri pada tahun 2019 di kota Banjar, Jawa Barat. Tercatat jumlah penduduk kota Banjar pada tahun 2018 sebanyak 201.348 yang jika dibandingkan dengan kota-kota lain akan berbeda jumlahnya. Kopi Kewadanan melihat adanya beberapa peluang dalam membangun bisnis coffee shop khususnya di kota tersebut, karena jumlahnya yang cukup sedikit menjadikan kesempatan dalam menghadapi persaingan. Salah satu faktor mengapa menjadi suatu peluang adalah di Indonesia sudah banyak berkembang coffee shop yang dipicu oleh taraf hidup dan pergeseran gaya hidup masyarakat. Tentunya hal tersebut mendorong adanya peningkatan dalam mengkonsumsi kopi di Indonesia pada era milenial sekarang. Terlebih jika coffe shop tersebut bagus dan instragamable. Maka dari itu segmentasi dari Kopi Kewadanan mengarah kepada kalangan anak muda.

Kopi Kewadanan memberikan konsep yang baru dan berbeda untuk masyarakat kota Banjar yang gemar mengkonsumsi kopi, dalam arti tidak seperti coffee shop pada umumnya. Adanya perbedaan yang diperlihatkan oleh Kopi Kewadanan dengan pesaing lainnya seperti desain interior dan eksterior yang dibuat agar konsumen merasakan suasana yang berbeda. Untuk segi produk, Kopi Kewadanan menjual kopi yang berkualitas premium namun memiliki harga yang dapat bersaing dengan coffee shop lainnya. Terlebih pilihan biji kopi yang beragam dapat menarik perhatian para pecinta kopi, seperti biji-biji lokal yang berkualitas hingga menghadirkan biji kopi yang berasal dari negara lain.

Strategi yang dilakukan oleh Kopi Kewadanan adalah dengan cara mempromosikan menggunakan media sosial Instagram karena hal itu merupakan salah satu cara yang ampuh di era yang sudah mulai semakin maju akan teknologi. Menurut Poppy Savitri, Direktur Edukasi Ekonomi Kreatif, seiring peningkatan konsumsi kopi di dunia, konsumsi kopi di Indonesia akan pun akan terus meningkat rata-rata lebih dari 7\% per tahun (Tribun News, 2018) dengan ketersediaan bahan baku kopi yang melimpah, kemudian tren gaya hidup semakin mendorong pertumbuhan tingkat konsumsi kopi tidak heran jika bisnis coffee shop menjadi bisnis yang diminati saat ini. Melalui Instagram, Kopi Kewadanan dapat dikenal oleh masyarakat Kota Banjar karena seperti yang terlihat pengaruh dari jumlah konsumsi kopi di Indonesia yang terus meningkat membuat masyarakat dapat menikmati kopi dimana saja dengan tempat yang berbeda.

Maka dari itu peneliti tertarik untuk mengetahui bagaimana strategi Branding yang dilakukan oleh Kopi Kewadanan dalam mengembangkan nama dari coffee shop tersebut dari memasarkan produk yang memiliki perbedaan tersendiri agar dapat bersaing dengan coffee shop lainnya sesuai pengelolaan yang baik serta untuk mendapatkan perhatian di benak masyarakat Kota Banjar.

"Bagaimana Strategi Branding yang dilakukan Kopi Kewadanan dalam menghadapi persaingan bisnis?"

\section{B. Landasan Teori}

\section{Komunikasi}

Komunikasi merupakan sebuah proses penyampaian pesan dari komunikator pada komunikan atau dapat dikatakan pula proses penyampaian pesan dari satu orang kepada orang lain dengan tujuan adanya proses saling mempengaruhi yang akan menghasilkan suatu efek. Thomas $\mathbf{M}$. Scheidel mengemukakan bahwa kita berkomunikasi terutama untuk menyatakan dan mendukung identitas- diri, untuk membangun kontak sosial dengan orang di sekitar kita, dan untuk mempengaruhi orang lain untuk merasa, berpikir, atau berperilaku seperti yang kita inginkan. Namun, menurut Scheidel tujuan dasar kita berkomunikasi adalah untuk mengendalikan lingkungan fisik dan psikologis kita (dalam Mulyana, 2015:4). 


\section{Brand}

Brand adalah firasat seseorang tentang produk, layanan, atau perusahaan. Orang jatuh cinta dengan brand, mempercayai mereka, dan percaya pada superioritas mereka. Bagaimana brand dirasakan mempengaruhi keberhasilannya. Dari beberapa definisi di atas dapat disimpulkan bahwa pada dasarnya merek adalah nama, istilah, tanda, simbol, atau desain atau paduan yang menggambarkan identitas produk baik barang ataupun jasa yang menjanjikan sebuah kualitas atau maksud merek tersebut.

\section{Brand Equity}

Brand equity perlu untuk terus dilakukan, karena pada dasarnya semakin lemah ekuitas suatu merek, maka merek tersebut akan semakin rentan terhadap masalah (Nicolino, 2007:78). Dengan terus menerapkan kegiatan brand equity didalam kelangsungan perusahaan, akan menghidari tanggapan negatif yang diberikan masyarakat kepada perusahaan.

\section{Brand Awareness}

Kesadaran merek adalah kesanggupan seorang calon pembeli untuk mengenali atau mengingat kembali bahwa suatu merek merupaka bagian dari kategori produk tertentu. Kesadaran merek memiliki fungsi sebagai mekanisme memperluas pasar merek, mempengaruhi persepsi dan tingkah laku, dan sebagai kunci pembuka untuk masuk ke elemen lainnya (key of brand asset). Brand awareness adalah ukuran kekuatan eksistensi suatu merek di benak pelanggan (Ambadar. 2007: 66). Brand awareness mencakup brand recoginition (merek yang pernah diketahui pelanggan), brand recall (merek apa saja yang pernah diingat oleh konsumen untuk kategori tertentu), top of mind (merek pertama apa yang disebut konsumen untuk satu produk) dan dominant brand (satu-satunya merek yang diingat konsumen).

\section{Brand Association}

Asosiasi merek mencerminkan pencitraan suatu merek terhadap suatu kesan tertentu dalam kaitannya dengan kebiasaan, gaya hidup, manfaat, atribut produk, geografis, harga, pesaing. Menurut Aaker, asosiasi merek adalah segala hal yang berkaitan dengan ingatan merek. Keterkaitan pada suatu merek akan lebih kuat jika dilandasi pada banyak pengalaman. Berbagai asosiasi yang diingat konsumen dapat dirangkai sehingga membentuk citra tentang merek atau brand image. Asosiasi merek dapat menciptakan nilai bagi perusahaan dan pelanggan karena dapat membantu penyusunan informasi untuk membedakan merek yang satu dengan merek yang lain.

\section{Brand Perceived Quality}

Kesan kualitas adalah mencerminkan persepsi pelanggan terhadap keseluruhan kualitas/keunggulan suatu produk atau jasa layanan berkenaan dengan maksud yang diharapkan. Terdapat lima nilai kesan kualitas: Pertama, alasan membeli. Kesan kualitas sebuah merek memberikan alasan yang penting untuk membeli. Hal ini memengaruhi merek-merek mana yang dipertimbangkan dan mana yang dipilih. Kedua, diferensiasi atau posisi dan ketiga adalah harga premium. Apakah merek tersebut merupakan yang terbaik. Selain itu dengan harga premium akan menciptakan kesan pelanggan memperoleh produk sesuai dengan apa yang dibayar. Keempat, meningkatkan minat para distributor, pengecer, dan saluran distribusi yang lain. Denga membawa citra produk yang berkualitas, distributor dapat menawarkan harga-harga dan menguasai niaga distribusi. Kelima, perluasan merek. Merek dengan kesan kualitas yang kuat dapat digunakan untuk memperkenalkan kategori produk baru yang beraneka macam. Produk yang memiliki kesan kualitas tinggi memiliki kemungkinan sukses yang lebih besar sehingga memungkinkan perolehan pasar yang lebih besar.

\section{Strategi Branding}

Menurut Lesser Robert, definition of strategy is a fundamental plan of action that is intended to accompish the company's objective.

Strategi Branding diartikan sebagai rencana yang berisikan gagasan yang ditujukan untuk membangun kesan terhadap konsumen terhadap sebuah produk barang atau jasa sehingga mampu mencapai target yang dikehendaki. 


\section{Instagram}

Instagram adalah sebuah aplikasi berbagai foto yang memungkinkan pengguna mengambil foto, menerapkan filter digital, dan membagikannya ke beragai layanan jejaring sosial, termasuk milik Instagram sendiri. Satu fitur yang unik di Instagram adalah memotong foto menjadi bentuk persegi, sehingga terlihat seperti hasil kamera kodak instamic dan polaroid. Hal ini berbeda dengan rasio aspek 4:3 yang umumnya digunakan oleh kamera pada peranti bergerak.

\section{Hasil Penelitian dan Pembahasan}

\section{Strategi Branding Kopi Kewadanan dalam Menghadapi Persaingan Bisnis Coffee Shop}

Pada penelitian kali ini penulis menemukan bahwa strategi Branding yang dilakukan oleh Kopi Kewadanan dalam menghadapi persaingan bisnis coffee shop yang berada di kota Banjar adalah dengan melakukan komunikasi melalui media sosial Instagram. Komunikasi yang dimaksudkan seperti yang dikemukakan oleh Thomas M. Scheidel dalam buku Deddy Mulyana (2015:4) bahwa kita berkomunikasi terutama untuk menyatakan dan mendukung identitas- diri, untuk membangun kontak sosial dengan orang di sekitar kita, dan untuk mempengaruhi orang lain untuk merasa, berpikir, atau berperilaku seperti yang kita inginkan.

Hal ini juga berkaitan dengan fungsi komunikasi seperti yang dikatakan oleh Onong U. Effendy (2003) yaitu:

1. Menginformasikan (to inform) yaitu memberikan informasi kepada masyarakat, memberitahukan kepada masyarakat mengenai peristiwa yang terjadi, ide atau pikiran, dan tingkah laku orang lain serta segala sesuatu yang disampaikan orang lain.

2. Kopi Kewadanan menginformasikan seluruh apa yang ingin diberikan untuk masyarakat kota Banjar melalui media sosial Instagram. Seperti Kopi Kewadanan menginformasikan bahwa mereka akan hadir tanggal 26 Februari 2019 yang diunggah di halaman utama Instagram Kopi Kewadanan. Selanjutnya menginformasikan Kopi Kewadanan buka yang diunggah pada Instagram Story.

3. Mendidik (to educate) yaitu sebagai sarjana pendidikan, dengan komunikasi manusia dapat menyampaikan ide dan pikirannya kepada orang lain sehingga orang lain mendapatkan informasi dan pengetahuan.

4. Dalam mendidik atau mengedukasi, Kopi Kewadanan cenderung melakukan hal tersebut dengan berinteraksi langsung karena sistem open bar yang diberlakukan sering kali konsumen yang menginginkan untuk belajar membuat kopi.

5. Mempengaruhi (to influence) yaitu fungsi mempengaruhi setiap individu yang berkomunikasi, tentunya dengan cara saling mempengaruhi jalan pikiran komunikan dan lebih jauh lagi berusaha merubah sikap dan tingkah laku komunikan sesuai dengan yang diharapkan.

Kopi Kewadanan menggunakan media sosial Instagram sebagai strategi Branding tentu bertujuan mempengaruhi masyarakat terutama followers dari akun Instagram untuk datang dan membeli produk dari Kopi Kewadanan. Seperti unggahan-unggahan foto produk, interaksi dengan konsumen, dan suasana menjadi salah satu faktor yang dapat mempengaruhi bagi yang melihatnya.

Dari definisi di atas maka dapat disimpulkan secara sederhana bahwa komunikasi itu merupakan sebuah proses untuk menyampaikan atau mengirimkan pesan dari satu orang ke orang lain dimana kedua orang tersebut dapat saling memahami apa makna yang disampaikan tersebut karena pada hakikatnya komunikasi yang baik adalah dimana antara komunikator dan komunikan dapat memahami apa makna, dan pesan yang disampaikan, dan di terima sehingga tidak terjadi sebuah miss communication atau kesalahan dalam memaknai sebuah pesan sehingga komunikasi yang berlangsung tidak berjalan efektif. Berkaitan dengan hasil temuan penelitian mengenai strategi Branding yang dilakukan oleh Kopi Kewadanan dalam menghadapi persaingan bisnis coffee shop di kota Banjar, hal paling dasar yang harus dilakukan adalah komunikasi. 
Komunikasi yang dilakukan oleh Kopi Kewadanan melalui media sosial Instagram dapat dikatakan secara transaksional yakni dua arah. Komunikasi yang terjalin bersifat saling menguntungkan dimana adanya proses timbalk balik antara Kopi Kewadanan dengan followers seperti model komunikasi Tubss yang mengemukakan komunikasi sebagai suatu transaksi. Model komunikasi Tubbs sesuai dengan konsep komunikasi sebagai transaksi, yang mengasumsikan kedua peserta komunikasi sebagai pengirim sekaligus juga penerima pesan. (Mulyana, 2014:166).

\section{Implementasi Strategi Branding Melalui Media Sosial Instagra}

1. Brand Equity Kopi Kewadanan

Melalui hasil penelitian yang dilakukan peneliti maka dapat diketahui bahwa implementasi atau pelaksanaan strategi untuk mem-Branding yang dilakukan oleh Kopi Kewadanan melewati beberapa tahap sebelum dilaksanakannya startegi tersebut. Dalam tahap perencanaannya Kopi Kewadanan melalukan riset terlebih dahulu melihat situasi pasar mengenai kopi di kota Banjar dengan terjun langsung ke lapangan. Setelah melakukan riset, Kopi Kewadanan menentukan konsep yang mereka katakan yang lebih matang jika dibandingkan coffee shop lainnya seperti yang pertama tempat yang Instagramable untuk interior dan eksterior. kedua, bekerjasama dengan influencer yang memliki pengaruh terhadap kalangan anak muda kota Banjar. ketiga, Kopi Kewadanan memberlakukan sistem open bar yang memungkinkan konsumen yang datang untuk membuat atau belajar membuat kopinya sendiri. Selain itu dari sistem open bar tersebut Kopi Kewadanan sekaligus memperlihatkan pelayanan yang friendly dari barista untuk konsumen. Setelah melakukan riset dan menentukan konsep, Kopi Kewadanan membuat konten dari apa yang telah direncanakan dan pada akhirnya konten tersebut diunggah di akun media sosial Instagram Kopi Kewadanan.

\section{Brand Awareness}

Kopi Kewadanan melalukan Branding melalui media sosial Instagram tentu memiliki tujuan agar followers atau masyarakat kota Banjar sadar akan terhadap merek yang mereka miliki. Apabila followers atau masyarakat sudah sadar terhadap merek tersebut, bukan tidak mungkin mereka akan menjadi pelanggan setia bagi Kopi Kewadanan. Untuk membangun brand awareness, Kopi Kewadanan membuat konten dari konsep yang telah ditentukan sebelumnya. Konten yang dibuat berisikan foto bagian ruang interior dan eksterior dari Kopi Kewadanan yang Instagramable. Dari foto tersebut memiliki pengaruh yang cukup baik dimana seperti yang dikatakan oleh salah satu konsumen yang datang merasa lebih aware dengan Kopi Kewadanan karena untuk tempatnya selain Instagramable juga nyaman dipakai tempat kumpul atau rapat dengan teman-teman. Tidak hanya itu, varian minuman terutama untuk beans yang ditawarkan terbilang cukup banyak dengan kualitas yang baik. Kopi Kewadanan menggunakan Instagram Story sebagai alternatif lainnya untuk menyebarkan informasi. Konsumen juga menambahkan akan kembali dan merekomendasikan kepada teman-temannya mengenai Kopi Kewadanan.

\section{Brand Association}

Strategi Branding yang dilakukan oleh Kopi Kewadanan melalui media sosial Instagram merupakan kegiatan yang secara tidak langsung memperlihatkan dari asosiasi merek yang mereka ciptakan. Unggahan-unggahan pada media sosial Instagram Kopi Kewadanan menggambarkan bagaimana konsep tempat kopi yang baru untuk masyarakat kota Banjar. Unggahan tersebut berupa tempat, suasana, lokasi, produk hingga pelayanan dan tidak hanya itu, unggahan yang diunggah oleh konsumen yang datang dan tag Kopi Kewadanan juga ikut diunggah secara berkala. Hal ini yang memberikan kesan-kesan tertentu terhadap Kopi Kewadanan itu sendiri dan mungkin akan tertanam di benak followers dan masyarakat. Selain itu, ini juga menjadi image tersendiri untuk Kopi Kewadan di mata masyarakat.

4. Brand Perceived Quality

Dalam membangun brand perceived quality atau kesan kualitas, Kopi Kewadanan memaksimalkan Branding yang mereka lakukan melalui media sosial Instagram. Unggahan pada Instagram Kopi Kewadanan yang memperlihatkan produk menjadi perhatian bagi followers. Seperti yang dikatakan oleh konsumen yang merupakan triangulasi pada penelitian 
ini, salah satu memberikan kesan yang cukup positif mengenai alasan mengapa mereka membeli produk dari Kopi Kewadanan yaitu karena dari varian minuman dan beans dari berbagai merek yang membuat konsumen tertarik untuk datang dan membeli produk Kopi Kewadan. Kedua, Kopi Kewadanan memberikan diferensiasi terhadap merek yang sedang mereka bangun agar dapat bersaing dengan merek coffee shop lain yang ada di kota Banjar. Owner menjelaskan bahwa konsep yang dimiliki oleh Kopi Kewadanan merupakan konsep yang lebih matang jika dibandingkan dengan coffee shop lainnya. Salah satunya adalah tempat yang Instagramable untuk konsumen yang gemar berfoto dengan teman atau keluarga. Ketiga, Kopi Kewadanan mengunggah varian beans yang mereka hadirkan untuk hari itu di Instagram Story. Hal ini sesuai dengan pernyataan narasumber yang mengatakan bahwa produk yang dijual memiliki kualitas premium namun harga dapat bersaing dengan coffee shop lainnya. Keempat, dalam hal ini owner masih bernegosiasi dengan roastery yang berlokasi di kota Bandung untuk bekerjasama dengan Kopi Kewadanan. Kelima, untuk perluasan merek dapat dikatakan bahwa Kopi Kewadanan masih percaya dengan media sosial Instagram yang digunakan dan word of mouth.

\section{Kesimpulan}

Strategi Branding yang dilakukan oleh Kopi Kewadanan adalah dengan menggunakan media sosial Instagram. Kopi Kewadanan memanfaatkan fitu-fitur yang ada pada Instagram seperti foto, video dan Instagram Story. foto dan video merupakan hal yang utama dalam penggunan media sosial Instagram. Pihak Kopi Kewadanan menyebarkan informasi mengenai coffee shop yang nantinya akan buka di kota Banjar pada awal tahun 2019. Informasi yang diunggah merupakan konten dari konsep Kopi Kewadanan yang telah direncanakan sebelumnya seperti foto interior dan eksterior, foto produk, foto interaksi barista dengan konsumen. Selanjutnya menggunakan Instagram Story yang berisikan foto dan video mengenai informasi seperti memberitahu bahwa Kopi Kewadanan sudah buka, produk terbaru yang akan hadir, repost unggahan dari konsumen, dan mengunggah unggahan dari influencer untuk membantu proses Branding yang dilakukan.

Strategi Branding dari Kopi Kewadanan mempunyai dua tahap yaitu perencanaan dan pelaksanaan. Pada tahap perencanaan yang dilakukan oleh pihak Kopi Kewadanan pertama kali adalah melalukan riset terlebih dahulu untuk melihat apa yang menjadi potensi dan mengetahui apa keinginan masyarakat kota Banjar mengenai kopi. Setelah melakukan riset dan mengetahui apa keinginan masyarakat, pihak Kopi Kewadanan menentukan konsep yang sesuai serta terbilang matang agar dapat bersaing dengan coffee shop lainnya. Konsep yang terbentuk adalah tempat yang Instagramable, bekerjasama dengan influencer untuk mempengaruhi target pasar yang sudah ditentukan dan sistem open bar dimana konsumen yang datang dapat belajar atau membuat kopi sendiri. Selain itu dari sistem open bar tersebut juga memperlihatkan pelayanan barista Kopi Kewadanan yang friendly. Kedua, membuat konten dari hasil konsep yang telah dibuat untuk selanjutnya dapat diunggah di media sosial Instagram Kopi Kewadanan.

Kopi Kewadanan menggunakan media sosial Instagram sebagai strategi Branding mereka adalah zaman yang semakin maju dan teknologi semakin canggih yang mampu memudahkan urusan bagi penggunanya, terlebih segmenatsi pasar yang dituju adalah kalangan anak muda khususnya pelajar. Selain itu asalannya karena Kopi Kewadanan bertujuan untuk memperkenalkan merek baru untuk coffee shop dan tentu untuk meningkatkan penjualan.

\section{E. Saran}

\section{Saran Teoritis}

1. Dalam membangun strategi Branding untuk sebuah brand, diperlukan strategi yang matang, efektif dan efisien guna tujuan dari strategi Branding tersebut dapat tercapai dan misi dari perusahaan pun terwujud. Pemaparan menurut ahli yaitu David Aaker tentang strategi Branding dapat di jadikan acuan bagi perusahaan.

2. Bagi mahasiswa yang akan melakukan penelitian mengenai Branding atau permerekan sebuah perusahaan, disarankan untuk meniliti dari sudut pandang lain yang berbeda dari penelitian ini. Karena strategi Branding banyak cakupannya yang dapat dibahas dan 
diteliti lebih dalam.

\section{Saran Praktis}

1. Kopi Kewadanan dalam melakukan Branding sudah cukup matang dalam segi strategi yang mereka lakukan menggunakan media sosial Instagram. Untuk kedepannya, pihak Kopi Kewadanan menentukan strategi bagaimana mereka dapat bertahan untuk bersaing dengan coffee shop lainnya melalui cara lain agar dalam membangun brand, Kopi Kewadanan dapat mencapai tujuan secara efektif dan efisien.

2. Kopi Kewadanan dapat memaksimalkan elemen - elemen dari strategi Branding yang lebih kreatif dan inovatif dan menjadi diferensiasi dengan brand lain agar Kopi Kewadanan dapat menjadi coffee shop yang lebih dikenal khalayak.

\section{Daftar Pustaka}

Duane E. Knapp. 2001. The Brand Mindset. Edisi Kedua. Yogyakarta: Andi.

Effendy, Onong Uchyana. 2003. Ilmu Komunikasi Teori dan Praktek. Bandung :Remaja Rosdakarya.

Gunawan, Imam. 2013. Metode Penelitian Kualitatif Teori \& Praktik. Jakarta : Bumi Askara.

Kaplan, Andreas. M. dan Haenlein. Michael. 2010. Users of the world unite! The Challenges and Opportunities of Social Media. Business Horizon.

Kertamukti, Rama, 2015. Strategi kretif dalam periklanan : Konsep Pesan, Media, Branding, Anggaran. Jakarta: Rajawali Press.

Puntoadi, Danis. Menciptakan Penjualan Melalui Social Media.Jakarta (ID) : PT Elex Komputindo. 2011

Rangkuti, Freddy. 2002. The Power of Brand (Teknik Mengelola Brand Equity dan Strategi Pengembangan Merek). Jakarta: Gramedia Pustaka Utama.

Yin, Robert K., (2009). Studi Kasus: Desain dan Metode. Jakarta: Penerbit Raja Grafindo Persada.

Pratama, Raditya, dkk. 2018. Analisis Brand Equity Perusahaan Melalui Media Sosial, dalam ejournal Unisba Vol. 54 (Hal 54). 